\title{
Neonatal aortic arch thrombosis
}

\author{
D J Evans, B L Pizer, N E Moghal, H S Joffe
}

\begin{abstract}
An infant presented shortly after birth with signs suggestive of aortic coarctation. Echocardiography revealed an extensive aortic arch thrombus, not amenable to surgery. Thrombolytic agents reduced thrombus size, enabling survival, but failed to prevent neurological damage secondary to cerebral embolisation. (Arch Dis Child 1994; 71: F125-F127)
\end{abstract}

Spontaneous neonatal aortic arch thrombosis is rare, with only six reported cases describing thrombus originating in the ascending aorta. Successful surgical repair with survival beyond the immediate postoperative period has only been described in two cases. In the case reported here, surgery was not possible due to the proximal extent of the thrombus; the patient was therefore managed with thrombolytic agents.

\section{Case report}

A boy was born at term, weighing $3420 \mathrm{~g}$, to a healthy primigravida mother. $\mathrm{He}$ was noted to be jittery and feeding poorly at 24 hours of age and had signs suggestive of aortic coarctation, namely a colour gradient with pale legs, right arm oedema, and absent left brachial and bilateral femoral pulses. A chest radiograph revealed mild cardiomegaly and pulmonary vascular congestion. Electrocardiography showed a mean QRS axis of $+130^{\circ}$ and normal precordial pattern.
The infant was commenced on a prostaglandin E2 infusion and transferred to the regional cardiothoracic unit for further investigation.

An echocardiogram demonstrated normal intracardiac structures and connections with a structurally normal aortic valve and no evidence of coarctation. There was a small left to right shunt across a patent foramen ovale, right ventricular hypertrophy and moderate tricuspid reflux, indicating raised right ventricular pressure. The most impressive finding was that of a large mass in the aortic arch, extending from just proximal to the innominate artery to beyond the left subclavian artery (fig 1). The mass was irregular in shape with an echodense envelope. It projected into the innominate and left carotid arteries, partially obstructing flow up both carotids, left subclavian artery, and down the aorta (gradient $35 \mathrm{~mm} \mathrm{Hg}$ ). There was no evidence of an intracardiac mass.

Magnetic resonance imaging (MRI) of chest and head was performed at 3 days of age. In addition to confirming the intra-aortic mass, it also showed areas of subacute infarction in the right frontal and left parietal cerebral cortex (fig 2A). Haemoglobin, platelet count, a clotting screen, and thrombophilia screen (including antithrombin III, protein $\mathrm{C}$ and $\mathrm{S}$ ) were all within the normal range for age. Both parents had normal protein $\mathrm{C}$ activity. A diagnosis was made of an aortic arch thrombus with cerebral embolisation.

Cardiopulmonary bypass or aortic cross clamping and surgical removal of the thrombus was not possible because it extended towards
Department of Cardiology, Bristol Royal Hospital for Sick Children, Bristol BS2 8BJ D J Evans

B L Pizer

N E Moghal

H S Joffe

Correspondence to: Dr Joffe.

Accepted 23 May 1994
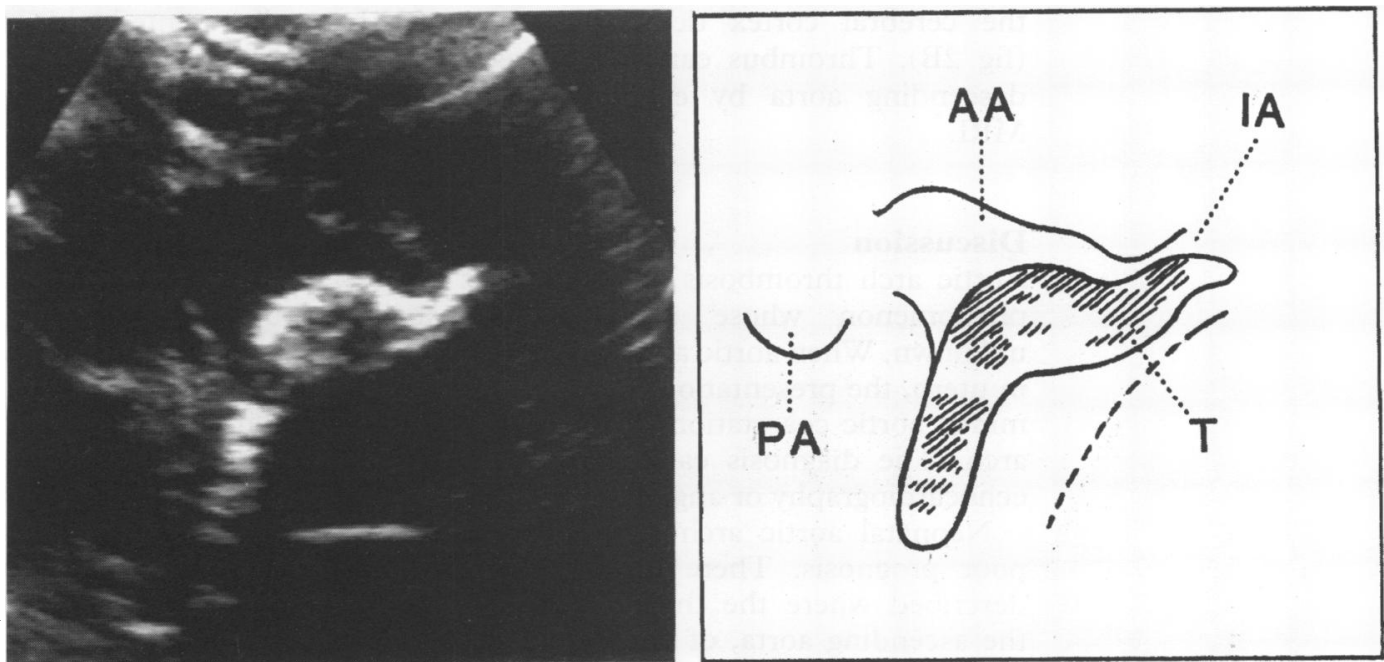

Figure 1 Two dimensional echocardiographic view in high right parasternal long axis plane showing the thrombus, partially lysed centrally, almost occluding the origin of the innominate artery. $T=$ thrombus, $L A=$ innominate artery, $A A=$ aortic arch, and $P A=$ pulmonary artery. 

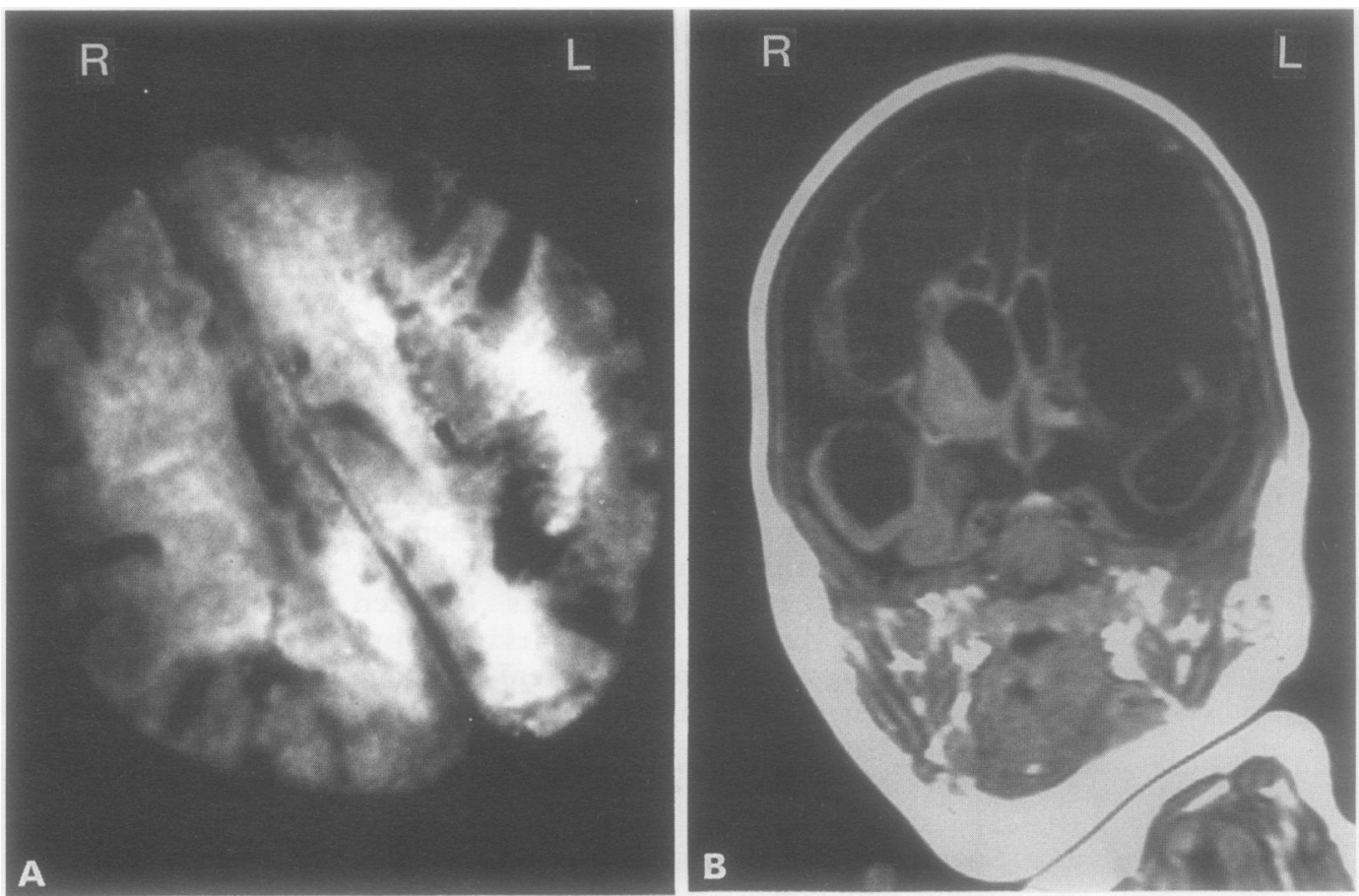

Figure 2 MRI of head: (A) T2 weighted image at 3 days of age, demonstrating areas of high signal in the left parieto-occipital and right frontal regions, consistent with oedema secondary to infarction; (B) T1 weighted image at 6 months of age, showing severe encephalomalacia: most of the cerebral tissue is replaced by fluid of cerebrospinal fluid density.

the aortic valve and was proximal to the innominate artery. The patient was treated with an infusion of streptokinase (1000 $\mathrm{IU} / \mathrm{kg} /$ hour) for six days, followed by heparin for a further nine days, and finally oral warfarin (maintaining an international normalised ratio of $2 \cdot 0-2 \cdot 5)$. The femoral pulses became palpable by the tenth day. Echocardiography on day 14 showed a slight reduction in the size of the thrombus and degree of aortic obstruction (gradient $15 \mathrm{~mm} \mathrm{Hg}$ ). However, surgery was still not thought feasible because of the abnormalities seen on cerebral MRI and the emergence of generalised seizures.

Now aged 6 months, the infant has continuing neurological impairment (spasticity, dystonia, seizures, and reduced visual awareness), with severe cystic encephalomalacia of the cerebral cortex demonstrated by $\mathrm{MRI}$ (fig 2B). Thrombus can still be seen in the descending aorta by echocardiography and MRI.

\section{Discussion}

Aortic arch thrombosis in neonates is a rare phenomenon whose aetiology is usually unknown. When aortic arch thrombosis occurs in utero, the presentation may, as in this case, mimic aortic coarctation or interrupted aortic arch. The diagnosis can be made by either echocardiography or angiography.

Neonatal aortic arch thrombosis carries a poor prognosis. There have been six cases described where the thrombus originated in the ascending aorta, of which four have been fatal. One patient died during attempted surgery $^{1}$ and another died postoperatively when rethrombosis of the ascending aorta occurred. ${ }^{2}$ In the third case, the infant's condition deteriorated with generalised convulsions and therefore surgery was not performed. ${ }^{3}$ This infant died of a cardiac arrest during streptokinase therapy with areas of cerebral ischaemic necrosis seen on postmortem examination. There have been two instances of patients surviving surgery, both involving thrombus originating distal to the innominate artery. ${ }^{45}$ In these cases, removal was possible by cross clamping the aorta both proximal and distal to the thrombus without compromising the blood flow into the innominate artery for any significant period of time. There has been only one case of a distal aortic arch thrombosis treated successfully with streptokinase; however, unlike the cases treated surgically, the infant was initially well and presented with impalpable femoral pulses on the tenth day. ${ }^{6}$

Fibrinolytic treatment may be more likely to succeed when the thrombus forms after the first few days of life. If the thrombus has developed earlier, it is more likely to be organised and fibrinolytic treatment is unlikely to result in its rapid dissolution. In this situation surgery may be the best option. In the case described, the aortic arch thrombus was unusual in that it extended from a point proximal to the innominate artery and therefore surgery was not felt possible. Fibrinolytic treatment was partly successful in reducing the thrombus bulk and the degree of obstruction to blood flow. However, there was significant morbidity from early embolisation to the cerebral circulation.

Neonatal aortic arch thrombosis is a rare phenomenon and the correct method of treatment is still debated. The case described 
illustrates that even if the infant survives treatment, there is a risk of severe continuing neurological impairment resulting from cerebral embolisation.

1 Ahmadi A, Furste HO, Pringsheim W, Spillner G, Keller KM, Bohm N, Schmidt-Redemann B. Congenital aortic thrombosis with complete obliteration of the aortic arch and the great vessels. Thorac Cardiovasc Surg 1983; 31: 256-9.
2 McFaul RC, Keane JF, Nowicki ER, Castaneda AR. Aortic thrombosis in the neonate. $\mathcal{F}$ Thorac Cardiovasc Surg 1981; 81: $334-7$.

3 Pilossoff W Schober JG, Muller KD, Schumacher G Sebening W, Babic R. Complete thrombotic obliteration of the ascending aorta and the aortic arch as a cause of acute heart failure in a newborn. Eur 7 Pediatr 1988; 148: 11-4. 4 Ninot A, Lambert A, Marchal C. Aortic arch thrombosis in a neonate. Pediatrie 1993; 48: 902-4.

5 Conti VR, Bilfinger TV, Wolf W. Aortic arch thrombosis in the neonate. F Thorac Cardiovasc Surg 1988; 95: 138-9. 6 Davidson A, Luhmer I, Kallfelz HC. Aortic arch thrombosis in the neonate. $\mathcal{F}$ Thorac Cardiovasc Surg 1989; 97: 152-3. 